\title{
Tradición y modernidad en la organización del discurso en español en el siglo XVIII
}

\author{
Tradition and modernity in the organization \\ of eighteenth century Spanish discourse
}

\author{
María Pilar Garcés Gómez \\ Universidad Carlos III de Madrid
}

Resumen. El objetivo de esta investigación es mostrar cómo se organiza el discurso en textos prosísticos del siglo XVIII, periodo de gran relevancia en la historia de la lengua española pues en él se desarrollan nuevos modelos de organización discursiva que se manifiestan en una forma de expresión más sencilla y a la vez más precisa y matizada. Nos centramos en el estudio de dos tipos de marcadores discursivos, de ordenación y de explicación, que presentan un empleo habitual en la prosa de esta época y que muestran, por un lado, una delimitación de las formas y una distribución de las funciones en los respectivos paradigmas y, por otro, la incorporación de nuevos signos y de nuevas funciones y valores discursivos en los ya existentes. El análisis nos permite demostrar que las funciones y valores discursivos que presentan estos marcadores en los textos escritos de la primera etapa del español moderno configuran los modos en que se establecerá la estructuración del discurso en los siglos XIX y XX, cuando se consolidan y se amplían estos usos. Las bases teóricas de la investigación se sustentan en los conceptos de gramaticalización por expansión, subjetivizacion y tradiciones discursivas; con los dos primeros se explican los factores internos que han motivado el desarrollo de estos marcadores discursivos hasta configurarse como tales en el Setecientos; el tercero permite dar cuenta de la incorporación, difusión y arraigo de los marcadores en diferentes géneros y modelos textuales.

Data de recepción: 14-09-2018 - Data de aceptación: 01-10-2018. 
Palabras clave: organización del discurso; español moderno; marcadores discursivos; gramaticalización por expansión; procesos de elaboración; tradiciones discursivas.

\begin{abstract}
The aim of this research is to show how discourse is organized in eighteenth-century prose texts, a period of great importance in the history of the Spanish language, since in that period new models of discourse organization were developed in the form of both simpler and more precise expression. We focus on the study of two types of discourse markers: order and explanation. These markers are frequently used in the prose of this period; the relevant properties are, first, the delimitation of form and the distribution of function in their respective paradigms and, secondly, the incorporation of new signs and the introduction of new functions and discourse values in addition to the existing ones. The analysis allows us to demonstrate that the discourse functions and values of these markers in the written texts of the first stage of modern Spanish configure the ways in which discourse structuring will be established in the nineteenth and twentieth centuries, when these are consolidated and expanded. The theoretical approach to this problem is based on the concepts of grammaticalization as expansion and subjectification, which serve to explain the internal factors that have motivated the development of these discourse markers in the eighteenth century, and the concept of discourse traditions in order to detail their incorporation, diffusion and consolidation in different genres and textual models.
\end{abstract}

Keywords: speech organization; modern Spanish; discourse markers; grammaticalization as expansion; process of elaboration; discourse traditions.

\title{
1. INTRODUCCIÓN Y OBJETIVOS
}

El análisis de la organización del discurso supone un acercamiento a los textos desde una perspectiva en la que es necesario tener en cuenta las relaciones que los distintos miembros del discurso establecen entre sí en un nivel supraoracional o extraoracional, así como aquellos aspectos relacionados con la producción y recepción de los textos y con su adecuada interpretación. Esta aproximación se ha desarrollado en el seno de disciplinas como la lingüística del texto, la pragmática lingüística o el análisis del discurso que proporcionan los instrumentos teóricos y metodológicos para abordar el estudio de fenómenos que están ligados a este nivel superior de análisis y al uso de la lengua en situaciones comunicativas concretas.

En el marco de la lingüística del texto, la atención se centra en los mecanismos de coherencia y cohesión, considerados como las dos propiedades fundamentales en la configuración de los textos (De Beaugrande \& Dressler 1981, entre otros). En el ámbito de la pragmática lingüística, desde la perspectiva de la Teoría de la relevancia, el interés se fundamenta en el proceso comunicativo y cognitivo; en este sentido, se considera que los discursos deben ser relevantes de modo que permitan 
La adopción de los conceptos y métodos de estas disciplinas en la investigación histórico-lingüística ha supuesto que el análisis textual se haya enriquecido considerablemente al tener en cuenta no solo aspectos fónicos, gramaticales o léxicos, sino también factores relacionados con la intención comunicativa del emisor, con la interpretación por parte de los destinatarios o con las relaciones que establecen los miembros discursivos entre sí; esta aproximación permite explicar adecuadamente el sentido de los textos y determinar los mecanismos de organización textual.

Desde esta perspectiva, el estudio de los marcadores discursivos adquiere una gran relevancia por su papel en la conexión de enunciados, o como reflejo de la actitud del hablante ante lo que expresa o de las relaciones establecidas entre los interlocutores. El acercamiento histórico al estudio de estos signos se ha realizado de dos maneras (Jacobs \& Jucker 1995, Brinton 2001, 2010, Hansen \& Rossari 2005): de una parte, el análisis diacrónico de la evolución de un determinado signo o de un conjunto de signos a través de las distintas etapas de su desarrollo ${ }^{2}$; de otra, el estudio de las formas, funciones y significados de estos elementos en un momento determinado de su etapa evolutiva, lo que constituye una visión sincrónica de la configuración de estas unidades discursivas en un determinado periodo temporal. En este segundo ámbito, en el que se inscribe nuestra investigación, los trabajos realizados se han ocupado preferentemente del funcionamiento de estos signos en las etapas del español medieval y clásico ${ }^{3} \mathrm{y}$, en las investigaciones más recientes, ese interés se ha extendido al español moderno ${ }^{4}$, periodo en el que se incorporan nuevos elementos, o adquieren nuevas acepciones los ya existentes, y se van conformando los distintos paradigmas de marcadores discursivos que se continuarán en el español contemporáneo.

a los interlocutores acceder a las inferencias necesarias para conseguir que la interpretación sea la más adecuada (Sperber \& Wilson $\left(1995^{2}\right)$.

2 Una relación de los estudios realizados sobre la evolución de un numeroso grupo de elementos que han adquirido la función de marcadores discursivos puede consultarse en Pons Rodríguez (2010). Entre otras contribuciones posteriores a esa fecha, pueden citarse Estellés (2011), Garcés Gómez (2009, 2011, 2013, 2014), Pons Bordería (2016), Pons Bordería \& Loureda Lamas (2018).

3 Para una visión conjunta de las funciones desempeñadas por los marcadores discursivos en la etapa medieval, puede consultarse Cano $(1999,2001,2002,2003)$ y para el español del siglo XVI Cano (2007); otras aportaciones se han ocupado del análisis de estas formaciones en autores concretos, en géneros específicos o en etapas más limitadas dentro los periodos medieval y clásico (cf. Pons Rodríguez 2010).

4 Los siglos XVIII y XIX representan un importante papel en el arraigo y extensión de nuevos marcadores discursivos, según se muestra en las investigaciones realizadas por diferentes autores: Melis, Flores \& Bogard (2003), Pons Rodríguez (2010, 2015), Espinosa Elorza (2012a, 2012b), Zamorano Aguilar (2012), Díez del Corral (2015), Flores \& Melis (2015), Pons Bordería (2016), Sáez Rivera \& Guzmán Riverón (2016), entre otros. 
En este marco, nuestro objetivo se centra en el estudio de la construcción del discurso en el siglo XVIII, cuando se produce una renovación de la prosa española en la que se tiende a la precisión y a la claridad y, como señalaba Lapesa (1981: 426), a falta de grandes cualidades estéticas «adquirió una sencillez de tono moderno que constituye su mayor atractivo». Para analizar cómo se organizan los textos escritos en prosa en esta época, fundamentaremos la investigación en el análisis de los valores y de las funciones que presentan dos grupos de marcadores que son fundamentales en la estructuración del discurso: los marcadores de ordenación, que señalan qué lugar ocupa cada uno de los miembros del discurso dentro de una secuencia ordenada por partes, y los marcadores de reformulación explicativa, que aclaran o explican lo expresado en el miembro anterior o presentan una nueva interpretación de lo que se ha pretendido decir.

La hipótesis de la que partimos y que pretendemos confirmar es que las funciones y valores discursivos que presentan estos marcadores en los textos escritos de la primera etapa del español moderno configuran los modos en que se establecerá la organización del discurso en los siglos XIX y XX, cuando se consolidan y se amplían estos usos.

En cuanto a la selección de los textos, hemos elegido obras en prosa que responden a diversas tradiciones discursivas, como el género ensayístico, predominante en este periodo, los tratados técnicos y científicos, el género epistolar o el género novelístico -lo que nos permitirá extraer conclusiones generales y delimitar las características específicas de determinados tipos de textos-, pertenecientes a autores españoles de este siglo que tienen un reconocido prestigio: Benito Jerónimo Feijoo (Teatro crítico universal, 1726-1740 y Cartas eruditas y curiosas, 1742-1760), José Cadalso (Los eruditos a la violeta, 1772; Cartas marruecas, 1789), Gaspar Melchor de Jovellanos (Memoria para el arreglo de la policía de los espectáculos y diversiones públicas y sobre su origen en España, 1790; Informe de la Sociedad Económica de Madrid, 1794), Ignacio de Luzán (Arte de hablar, 1729; Defensa de España y participación en la campaña contra Gregorio Mayans, 1742; La Poética, 1737-1789), José Francisco de Isla (Historia del famoso predicador Fray Gerundio de Campazas alias Zotes, 1758), Leandro Fernández de Moratín (Cartas, 1787-1792, La derrota de los pedantes, 1789), Gregorio Mayans (Orígenes de la lengua española, 1737), Juan Pablo Forner (Discursos filosóficos sobre el hombre, 1787), Juan Meléndez Valdés (Discursos forenses, 1791-1809).

Para la selección de los ejemplos, hemos utilizado los corpus CORDE y $C D H$ de la Real Academia Española y el Corpus del español de Mark Davies, así como los textos completos de las obras que 
Esta investigación se estructura en los siguientes apartados: tras esta introducción en la que se establecen los objetivos principales (1), se presentan las bases teóricas y metodológicas en las de que se basa el estudio de los marcadores discursivos en su perspectiva diacrónica (2), se analiza el modo en que se estructura el discurso mediante el empleo de los marcadores de ordenación en el Setecientos (3), se muestra la manera en la que se organizan los textos mediante el uso de los marcadores de reformulación explicativa en esta misma etapa (4) y, en la última sección, se establecen las conclusiones generales (5).

\section{LA FORMACIÓN Y DESARROLLO DE LOS MARCADORES DISCURSIVOS DESDE UNA PERSPECTIVA DIACRÓNICA}

Para explicar el proceso de cambio lingüístico experimentado por los elementos que han adquirido la función de marcadores discursivos $\mathrm{y}$, en concreto, los de ordenación y reformulación explicativa, es necesario tener en cuenta las diversas propuestas realizadas en el marco de la gramaticalización o en su nueva dimensión más abarcadora denominada construccionalización (Traugott \& Trousdale 2013).

En su versión tradicional, la Teoría de la gramaticalización pretende dar cuenta del proceso de cambio por el que unidades léxicas o construcciones adquieren funciones gramaticales en determinados contextos lingüísticos o una unidad gramatical desarrolla una nueva función gramatical (Hopper \& Traugott 20032: 1). Esta consideración supone que se trata de un proceso que va del léxico a la gramática o de lo menos gramatical a lo más gramatical, de carácter unidireccional y acompañado de una serie de parámetros (Lehmann 1995) como la pérdida o reducción del cuerpo fónico y del significado léxico, la integración paradigmática, la obligatoriedad, la limitación del alcance sintagmático, la fusión de palabras independientes o la fijación en una posición determinada, junto con un proceso de descategorización o el paso de un significado más referencial a menos referencial. Estos requisitos que se dan en los procesos de carácter estrictamente gramatical no permitían dar cuenta de la evolución de los marcadores discursivos, ya que estos elementos solo comparten algunas características señaladas para este tipo de gramaticalización ${ }^{6}$ como el proceso de descategorización,

nos proporciona la Biblioteca Digital Hispánica $(B D H)$ y la Biblioteca Virtual Miguel de Cervantes $(\mathrm{CV})$. En cuanto a la representatividad de las obras de estos autores en el corpus CORDE, son de gran interés las observaciones de Octavio de Toledo y Huerta (2016).

6 Esta aproximación se denomina "Grammaticalization as Reduction and increased dependency" (Traugott 2010a: 272; Traugott \& Trousdale 2013: 100) y permite explicar procesos de cambio como la conversión de verbos principales en morfemas de tiempo, modo o aspecto en la formación de los 
de fijación sintagmática o la generalización de significados, pero no se adaptan a otros mecanismos de este proceso, dado que pueden adquirir mayor autonomía sintáctica y ampliar su alcance predicativo.

Por otra parte, el desarrollo evolutivo de los marcadores discursivos implica que unidades con un significado léxico determinado y una función sintáctica en el nivel oracional pierdan parcial o completamente su significado conceptual y su función en el marco de la oración y se transformen en elementos invariables que adquieren un significado de procesamiento y pasan a desempeñar funciones discursivas y pragmáticas, este hecho ha llevado a algunos autores a considerar que la creación de estos signos debe explicarse como un proceso de pragmaticalización (Claridge \& Arnovick 2010: 187) o de discursivización (Elvira 2015: 193).

Una nueva aproximación a la gramaticalización como expansión ${ }^{7}$ permite ampliar las posibilidades del modelo tradicional y considerar que rasgos como la reducción estructural o el incremento de la dependencia solo deben ser considerados obligatorios en determinados dominios, pero en otros, como el de la formación de los marcadores discursivos, los elementos gramaticalizados no tienen que quedar fijados en una posición sintáctica, dado que adquieren libertad de movimiento, y no se convierten en signos más dependientes, pues amplían su alcance e inciden sobre todo el enunciado.

Este proceso no se desarrolla en unidades aisladas, sino que está vinculado a una construcción determinada y se produce en contextos específicos. De ahí que la construcción considerada como «un apareamiento de forma y significado arropado en una colocación o distribución exclusiva de ese apareamiento» (Company Company 2016: 523) sea la unidad que propicia el inicio del cambio y la construccionalización, considerada como un cambio diacrónico, implique el desarrollo de nuevas formas y de nuevos significados en una determinada construcción (Traugott \& Trousdale 2013: $22)^{8} \mathrm{y}$, en consecuencia, de nuevas funciones.

El cambio semántico que ha dado lugar a este proceso se origina en las situaciones concretas de uso en que se emplean estas unidades o construcciones cuyo significado

tiempos compuestos (he cantado) o del futuro (cantaré) o la creación de los adverbios en -mente a partir de dos palabras plenas (felizmente).

7 Este acercamiento se etiqueta como "Grammaticalization as Expansion" (Traugott 2010a: 276; Traugott \& Trousdale 2013: 105) y da cuenta del proceso evolutivo de elementos que pasan de desempeñar una función en el marco de la oración a desarrollar funciones en el ámbito del discurso.

8 Este planteamiento se enmarca en el modelo de la gramática construccional (Goldberg 2006, Croft 2007), donde el concepto de construcción envuelve pares de forma y significado en los que la forma incluye propiedades fonológicas, morfológicas y sintácticas y el significado propiedades semánticas, pragmáticas y discursivas (Traugott \& Trousdale 2013: 8). 
se modifica; según el modelo de cambio lingüístico por inferencias asociadas propuesto por Traugott \& Dasher (2002), este proceso comienza cuando el hablante modifica el significado codificado a partir de las inferencias asociadas que surgen en una situación y contexto concretos; si ese cambio se amplía y es aceptado por la sociedad se desarrollan las inferencias convencionales generalizadas que se mantienen mientras el significado original es dominante o igualmente accesible, pero cuando el significado original desaparece o se convierte en un mero rasgo en ciertos contextos, las inferencias convencionales generalizadas se consideran semantizadas como un nuevo significado codificado 9 .

En el desarrollo evolutivo de los marcadores discursivos analizados en esta investigación, este proceso de cambio semántico se manifiesta en una tendencia denominada subjetivización que supone el desarrollo de significados que codifican las creencias, actitudes o valoraciones del hablante/escritor ante lo que manifiesta y, en algunos casos, se puede desarrollar una tendencia a la intersubjetivización que supone codificar significados centrados en la atención del hablante/escritor hacia la imagen del destinatario (Traugott 2010b: 22) ${ }^{10}$.

Estos nuevos significados surgen, en la mayoría de los casos, por la convencionalización de inferencias pragmáticas en un determinado contexto, de modo que el cambio se considera, en general, de naturaleza inferencial metonímica, pues la totalidad del proceso que se desarrolla entre la aparición de una determinada inferencia en un contexto concreto hasta su convencionalización y consolidación como un nuevo significado se realiza por asociación o contigüidad dentro de un mismo dominio cognitivo (Traugott \& König 1991, Koch 2001, 2004, Traugott \& Dasher 2002) ${ }^{11}$.

$9 \quad$ Este proceso es gradual por lo que en el paso de un significado a otro pueden documentarse los denomimados contexto puente -"bridging contexts" (Heine 2002: 84) o "critical contexts" (Diewald 2002: 109)- que hacen referencia a contextos intermedios entre los que todavía es posible una doble interpretación entre el significado antiguo y el significado innovador antes de llegar a los contextos en los que solo cabe la interpretación del nuevo significado -"switch contexts" (Heine 2002: 85) o "isolated contexts" (Diewald 2002: 104)-.

10 Según había señalado Traugott (1995: 32): «'Subjectification in grammaticalisation’ is, broadly speaking, the development of a grammatically identifiable expression of speaker belief or speaker attitude to what is said. It is a gradient phenomenon, whereby forms and constructions that at first express primarily concrete, lexical, and objective meanings come through repeated use in local syntactic context to serve increasingly abstract, pragmatic, interpersonal, and speaker-based functions». De este modo, un gran número de cambios semánticos se explica por el uso expresivo del lenguaje, por el enriquecimiento pragmático de elementos léxicos como motor de cambio en los primeros estadios de la gramaticalización.

11 No obstante, en determinados procesos evolutivos, el cambio semántico puede explicarse como una transferencia metafórica del significado en el que se produce la proyección de un dominio 
Como consecuencia de estos procesos de cambio semántico, los sintagmas originarios han experimentado una serie de cambios morfológicos y sintácticos que se manifiestan en los siguientes aspectos: 1) un proceso de fijación por el que formas independientes se constituyen como locuciones fijas; 2) una mayor autonomía, ya que se convierten en expresiones independientes del resto del enunciado; 3) un cambio de comportamiento sintáctico pues dejan de realizar una función dentro de la predicación oracional y pasan a desempeñar funciones textuales o interpersonales periféricas respecto de la oración en la que aparecen; 4) un alcance estructural distinto, ya que no ejercen una función en el marco oracional, sino en el plano discursivo y 5) un proceso de reanálisis por el que formas procedentes de categorías gramaticales diversas se convierten en una categoría funcional de marcadores discursivos con las características formales señaladas y un nuevo significado en el que se han reforzado los valores pragmáticos.

Un proceso distinto experimentan aquellos elementos que se incorporan directamente al castellano con una función discursiva ya conformada, sin haber experimentado un proceso evolutivo previo, mediante la adaptación, traducción, calco o préstamo de formas existentes en otras lenguas o tradiciones discursivas más elaboradas donde ya ejercían esta función discursiva. Este desarrollo está relacionado con el concepto de elaboración lingüística ${ }^{12}$ e implica ampliar las propiedades formales y funcionales de una lengua histórica para configurarla como una lengua de cultura y convertirla en instrumento capaz de producir cualquier género textual o tradición discursiva (Jakob $\&$ Kabatek 2001: VIII). Estos cambios están vinculados a los requisitos de un discurso elaborado, planificado, de la distancia comunicativa y de concepción escrita (ibid.: IX).

Desde nuestra perspectiva, los procesos de cambio experimentados por los marcadores de ordenación y de reformulación explicativa, cuyos valores y funciones analizaremos en los siguientes apartados, deben situarse, en la mayoría de los casos, en el marco de la gramaticalización por expansión con las características señaladas para los signos que presentan este tipo de desarrollo evolutivo, y, en otros casos concretos -esto es, a saber-, pueden vincularse con un proceso de elaboración lingüística que

cognitivo a otro (Sweetser 1990); como ejemplo, se puede señalar la evolución del adverbio encima como marcador aditivo: a partir de la noción de superioridad expresada por el adverbio 'en lugar o puesto superior, respecto de otro inferior' se produce una reinterpretación en el plano textual en términos de superioridad argumentativa; de este modo, el enunciado introducido por este marcador se suma a los anteriores como un argumento más fuerte para llegar a una determinada conclusión (Garachana 2008).

12 Este concepto de elaboración lingüística y construcción de una lengua -“Sprachbau"- fue propuesto por Kloss (1967) y desarrollado por Koch \& Oesterreicher (1990/2007) y Oesterreicher 1997, 2007). 
supone la incorporación de estos signos como calcos semánticos del latín al castellano a través de determinadas tradiciones discursivas.

\section{LA ORDENACIÓN DEL DISCURSO Y SUS MARCADORES EN LOS TEXTOS DEL SIGLO XVIII}

Los marcadores de ordenación discursiva se caracterizan por señalar el lugar que ocupa cada uno de los miembros en una secuencia discursiva ordenada en partes y por indicar que la información presentada se manifiesta como una sucesión de comentarios y subcomentarios que responden a un mismo tópico o a tópicos distintos (Van Kuppevelt 1995a, 1995b, Portolés 2001², Garcés Gómez 2008).

La tipología de los marcadores de ordenación del discurso está determinada por el lugar que ocupa cada uno de los elementos de la serie y así se clasifican en tres tipos: a) marcadores de inicio, que señalan el comienzo de una serie de elementos concatenados entre los que puede establecerse o no una ordenación jerárquica; b) marcadores de continuación, que indican el desarrollo de una serie correlativa que puede ser abierta o venir delimitada en las partes que la componen; c) marcadores de cierre que introducen el último miembro discursivo de una serie ordenada secuencialmente (Martín Zorraquino \& Portolés 1999, Portolés 2001², Garcés Gómez 2008).

Los ordenadores del discurso se constituyen a partir de bases léxicas procedentes de la numeración -(lo) primero, (lo) segundo ... (lo) último-, de la estructuración espacial (por un lado... por otro; en primer lugar... en segundo lugar ...) o temporal (en cabo, a la postre, al fin, en fin, finalmente, por fin). El paso a la función discursiva se realiza en los dos primeros grupos a través de un proceso de gramaticalización por expansión que implica cambios morfológicos y sintácticos, dado que estos elementos se constituyen como sintagmas fijos, con movilidad posicional, situados al margen de la predicación oracional, y cambios semánticos de carácter inferencial metonímico que suponen que su valor originario de indicar la localización en el espacio o la sucesión en el tiempo se reinterprete como una sucesión y ordenación de los miembros en el discurso a través de una convencionalización de inferencias discursivas; de este modo, adquieren el sentido de señalar las partes en las que se organiza la información tanto en las secuencias expositivas como en las narrativas o descriptivas.

En el proceso evolutivo de las formaciones que se constituyen a partir de una base léxica relacionada con la indicación de 'fin', 'límite', o 'punto en el que acaba algo en el espacio o en el tiempo', se parte, en unos casos, de un significado inicial de cierre de una secuencia temporal tras la sucesión de una serie de hechos o acontecimientos previos y, por un proceso de cambio semántico de carácter metonímico inferencial, la 
sucesión temporal pasa a considerarse como una ordenación interna de los miembros del discurso, por lo que estos marcadores introducen el último segmento, de donde se derivan otros valores discursivos -reconsideración en al cabo, al fin y a la postre, reformulación en en fin y valores modales en al fin y por fin-, tras haberse desarrollado un proceso de gramaticalización por extensión; en otros, como en el caso de finalmente el valor temporal y discursivo se manifiesta desde las primeras documentaciones por lo que puede explicarse por un proceso de elaboración lingüística a través de una adaptación de la forma latina tandem que ya presentaba estos valores en los textos medievales y que se traspasan directamente a la forma romance equivalente (Garcés Gómez 2006, Iglesias 2007); a partir de este significado, experimenta un proceso de cambio semántico, por analogía con el que había desarrollado previamente la locución adverbial en fin, por el que adquiere un valor de reformulación que solo se mantendrá en la época áurea.

2.1 Los marcadores de inicio. Este grupo de marcadores se había originado en diversos periodos a lo largo de la historia de la lengua: en la época medieval, desde el siglo XIII, se documenta el adverbio primeramente ${ }^{13}$, así como la serie lo primero... lo segundo; de aparición posterior es la correlación primero, segundo, tercero, documentada desde comienzos del siglo XV, y ya en la época clásica, a finales del XVI, surge la serie correlativa en primer lugar, en segundo lugar, en tercer lugar. De este modo, el conjunto de estos marcadores ya estaba constituido en el siglo XVIII ${ }^{14}$.

En los textos analizados, la ordenación de los miembros de una serie discursiva puede establecerse entre actos de enunciación, en construcciones en las que los enunciados sobre los que inciden estos marcadores incluyen un verbo de lengua que expresa el acto de habla realizado y en las que se marca una sucesión de los distintos aspectos que se van a tratar sobre una misma materia; en el ejemplo siguiente (1), la ordenación de los segmentos discursivos se establece con un segundo miembro introducido por el adverbio después que no presenta un valor temporal, sino que expresa el orden en el que se suceden los temas que el autor desarrollará en su exposición (primeramente... después... últimamente):

(1) I assí, primeramente explicaré qué cosa es lengua, para que mejor se sepa qué deva entenderse por lengua española. Después señalaré sus orígenes generales; a los quales

13 Los correlatos segundamente, terceramente... registrados, asimismo, en el XIII desaparecen a partir del XVI y son sustituidos por las formas pertenecientes a las nuevas series correlativas.

14 El análisis de la evolución de los marcadores de ordenación discursiva puede consultarse en Garcés Gómez (2006). 
seguirán los principios i las reglas que se deven saber i guardar para averiguar los particulares. I últimamente apuntaré las perfecciones que por sí tiene nuestra lengua i las demás que puede recibir (Gregorio Mayans y Siscar, Orígenes de la lengua española, $1737, C D H)$.

En otros casos, se trata de una sucesión de argumentos, cuyo número viene delimitado en un segmento anterior, y cada uno de ellos puede aparecer precedido por marcadores pertenecientes a series distintas (2):

(2) Aristóteles atribuye el defecto de las fábulas episódicas a dos motivos: primeramente, a la ignorancia de aquellos poetas que, no sabiendo las reglas del arte, llenaban de episodios incoherentes sus tragedias y comedias, por no tener otro modo de hacerlas maravillosas y deleitables; en segundo lugar lo atribuye a que algunos, aunque no ignoraban las reglas, se inducían a violarlas por complacer a los representantes que deseaban poder lucir más tiempo en las tablas y ostentar más su habilidad (Ignacio de Luzán, La Poética, 1737-1789, CDH).

Cuando se establece una sucesión de razonamientos en apoyo de una conclusión manifestada previamente, el ordenador que señala el inicio de la serie puede llevar como correlatos otros marcadores de tipo argumentativo, como además, que añade un argumento coorientado y en la misma línea argumentativa que el anterior, o incluso, que establece una escala argumentativa (Sánchez López 1999; Martín Zorraquino \& Portolés 1999: 4075) en la que el segmento introducido por el marcador es más fuerte argumentativamente y añade un rasgo de 'contraexpectación', ya que no resultaba esperable en ese contexto:

(3) De ello no hay que culpar únicamente a la ignorancia de los maestros, ni me atrevería a afirmar que sean todos ignorantes; antes bien sospecho que ello se debe a muchas otras causas. En efecto, y en primer lugar, nuestros niños entran demasiado pronto en la escuela de la Gramática, y todo lo que aprenden en esa edad lo aprenden como papagayos, y no pueden retener por mucho tiempo las reglas en sus demasiado tiernas mentes. Además, la mayoría sólo persiste en el aprendizaje de la lengua latina dos años o a lo sumo tres, e inmediatamente se entrega al estudio de la Lógica, cuando apenas posee un conocimiento rudimentario de las reglas de la Oratoria; casi todos, incluso, las desprecian como inútiles, por pernicioso y común error, y ni llegan a catarlas (Ignacio de Luzán, Defensa de España y participación en la campaña contra Gregorio Mayans, $1742, C D H)$.

Esta ordenación argumentativa se manifiesta especialmente en secuencias expositivas en textos de tipo ensayístico, técnico y científico; en otros géneros, como el 
epistolar o el novelístico, estos marcadores se emplean en secuencias narrativas con el fin de establecer una ordenación de los hechos acaecidos (4):

(4) El inventor del solemnísimo cedulón no se paró en esas menudencias. Tiró, lo primero, a acreditarse de otro Cornelio Schrevelio en la inteligencia de la lengua griega para con los ignorantes de ella; y pretendió, lo segundo, aturrullar los oídos del populacho con esas voces barbarisonantes, sin habérsele pasado otra cosa por la imaginación (José Francisco de Isla, Historia del famoso predicador Fray Gerundio de Campazas alias Zotes, 1758, $\mathrm{CDH}$ ).

En algunos casos, el elemento que inicia una serie no tiene un correlato posterior y su empleo se justifica para señalar la relevancia que se atribuye a lo que se expresa en ese enunciado o segmento de enunciado en relación con los miembros que se añaden a continuación (5).

(5) He dicho, que el hecho es cierto. Porque en primer lugar es indubitable que la alma es la que ve, la que oye, la que huele, \&c., pues la materia es incapaz de percepción alguna, y solo organizada de este, o aquel modo, puede servir de instrumento para aquellas percepciones de el alma, la qual tampoco, sin el órgano corpóreo, puede exercerlas (Benito Jerónimo Feijoo, Cartas eruditas y curiosas, IV, 1753, CDH).

2.2 Los que marcan las partes en las que se divide una serie. Estos elementos señalan que el enunciado aparece dividido en dos subcomentarios que responden a un mismo tópico. Los correlatos indefinidos lo uno... lo otro ${ }^{15}$, surgidos en la etapa medieval, se mantienen con una escasa frecuencia en el XVIII y así va a continuar en los siglos posteriores. En cambio, las estructuras correlativas formadas con los sustantivos parte o lado, con un significado originariamente espacial que experimentan un cambio semántico por el que el espacio físico se reinterpreta como espacio discursivo y pasan a señalar la distribución de las partes en el discurso, son las utilizadas habitualmente por los escritores de este siglo. Algunas de estas correlaciones habían surgido en etapas anteriores: las primeras documentaciones son las de los pares de una parte...

15 Esta correlación registrada en el siglo XIII sustituye desde el siglo XV a la estructura predominante en la etapa medieval lo uno... lo al. En los textos analizados, solo aparece en el siguiente ejemplo: «El calor de el Sol, u otro qualquiera, sin duda evaporiza las partes más sutiles y fluidas de el agua; assí dexará el resto más gruesso, glutinoso y pesado; pues debemos suponer que ninguna agua es perfectamente homogénea; lo uno, porque siempre están mezclados en ella muchos corpúsculos sólidos; lo otro, porque ni aun las partes líquidas son de igual fluidez, lo que fácilmente notamos en las aguas de distintas fuentes» (Benito Jerónimo Feijoo, Suplemento de el Teatro Crítico Universal, España, 1740, $C D H)$. 
de otra (parte) en el XIV, por una parte... por otra (parte) en el XV; más tardía es la aparición de los otros dos tipos: por un lado... por otro (lado), en el XVII, y de un lado... de otro (lado), en el XVIII. No obstante, las construcciones más frecuentes en este periodo son las constituidas por las dos primeras series $(6,7,8)$ :

(6) Siendo los frutos de la tierra el producto inmediato del trabajo, y formando la única propiedad del colono, es visto cuán sagrada y cuán digna de protección debe ser a los ojos de la ley esta propiedad, que de una parte representa la subsistencia de la mayor y más precisa porción de los individuos del Estado, y de otra la única recompensa de su sudor y sus fatigas (Gaspar Melchor de Jovellanos, Informe de la Sociedad Económica de Madrid, 1794, $C D H)$.

Estas correlaciones pueden ir precedidas por conjunciones que rigen un grupo complejo formado por dos miembros que responden a un tópico común; en estructuras concesivas, como en el siguiente ejemplo (7), aunque señala que el impedimento establecido en el primer miembro no supone que lo expresado en el segundo segmento de la correlación se considere más importante, lo que implica, además, un cambio de perspectiva enunciativa:

(7) [...] pues aunque por una parte no es bien hablar yo mismo de mis Obras con aprecio y passión, porque esto sería ofender a la Modestia, por otra parte, despreciándolas y abatiéndolas más allá de lo justo ofendería también a la Sinceridad (Ignacio de Luzán, Defensa de España y participación en la campaña contra Gregorio Mayans, 1742, $\mathrm{CDH})$.

En otro tipo de estructuras como las condicionales (8), se documentan ejemplos en los que la prótasis aparece dividida en dos bloques informativos precedidos por la conjunción $s i$, que representan dos argumentos -según se indica explícitamente en el texto: este doble argumento- que conducen a la conclusión que se manifiesta en la apódosis; estos pares correlativos señalan el paso de un segmento a otro, que tienen referentes distintos y puntos de vista diferenciados:

(8) Igual prueba puede deducirse por un argumento a posteriori; pues si de una parte es notorio que algunas provincias en años comunes consumen algún trigo extranjero, de otra lo es también que no hay provincia alguna que en años comunes extraiga trigo nacional; y este doble argumento, fácil de comprobar por las aduanas, basta para concluir contra la existencia del sobrante en años comunes (Gaspar Melchor de Jovellanos, Informe de la Sociedad Económica de Madrid, 1794, CDH). 
2.3 En esta etapa se muestran ya constituidas las formaciones por otra parte, de otra parte y se incorporan las que tienen como base el sustantivo lado: por otro lado, de otro lado. Cuando estos marcadores aparecen sin un primer correlato, su valor general es el de marcar una transición entre las distintas partes del discurso estableciendo entre ellas diferentes tipos de relaciones: el paso de un aspecto a otro del mismo tópico, el cambio de un tópico a otro distinto o la introducción de un comentario digresivo.

En el primer caso, la información se presenta estructurada en dos segmentos informativos equivalentes y el miembro introducido por el marcador de otro lado es la segunda parte al tópico del que se está tratando -la injusticia en las decisiones judiciales-, en correlación con un segmento discursivo anterior que puede ser considerado como una primera parte del comentario a ese mismo tópico:

(9) [...] si notásemos la ley, guiando como por la mano al ciudadano, y la prudencia de otro lado advirtiéndole para que desconfíe y se resguarde; si la astucia sagaz le tendiese sus redes, y ni la rectitud ni la verdad bastasen á librarle de su enmarañado laberinto, clamemos también sobre estos gravísimos objetos (Juan Meléndez Valdés, Discursos forenses, 1791-1809, CDH).

Una función diferente se registra cuando el marcador establece una transición entre comentarios que responden a tópicos distintos -la culpabilidad ante un delito en el primero, el modo de evitar un delito, en el segundo-, como en el ejemplo siguiente (10), donde se hace referencia a dos situaciones relacionadas que se muestran como contrapuestas, según indica el conector contraargumentativo pero precediendo al marcador:

(10) No niego que en igualdad de delito es más culpable el que con menor incentivo peca; pero, por otra parte, es menester atender a que a mayor incentivo se debe aplicar más fuerte freno, y el freno no es otro que el temor del castigo (Benito Jerónimo Feijoo, Teatro Crítico Universal, VI, 1734, CDH).

Un tercer empleo se documenta cuando el marcador introduce un comentario digresivo referido a uno de los sintagmas del enunciado; se trata de una información marginal que se añade al contenido expresado en el sintagma previo, y que aparece situada entre incisos porque es un segmento que el hablante/escritor desea enfatizar en el plano informativo (11).

(11) Es grande el número de los que se deleitan en mentir, pero mucho mayor el de los que se deleitan en mentir prodigios y portentos. Aun hombres, por otra parte bastante veraces, 
caen una y otra vez en esta tentación, como en varias ocasiones he observado (Benito Jerónimo Feijoo, Teatro Crítico Universal, VIII, 1739, CDH).

2.4 Los marcadores de cierre discursivo experimentan en este periodo varios cambios en su paradigma. Formaciones como al cabo, a la postre y al fin que habían presentado un valor de cierre discursivo desde el siglo XIII y lo mantienen de manera continuada hasta el siglo XVI -en el caso de al cabo y a la postre- y hasta el XVII -en el de al fin- ya no lo conservan en el siglo XVIII, aunque todavía puede registrarse algún ejemplo esporádico de este uso ${ }^{16}$ debido a preferencias individuales o a motivos estilísticos. En el Setecientos, estas formaciones muestran un valor de reconsideración de lo expresado en los miembros anteriores a fin de presentarlo desde una nueva perspectiva en apoyo o en oposición a una propuesta anterior parcial o totalmente ${ }^{17}$; este valor, desarrollado a partir de los contextos en los que se justifica una aseveración final tras haber tenido en cuenta otras posibles expectativas anteriores y documentado desde finales del XV, se mantendrá durante este siglo, pero ya desde la segunda mitad $\mathrm{y}$, especialmente, en el XIX está en retroceso en relación con las construcciones coordinadas al fin y al cabo y al fin y a la postre, que se convertirán en los marcadores de reconsideración prototípicos. Por otra parte, a partir de su valor inicial de señalar un suceso final que cierra o culmina una serie de ellos, al fin adquiere un nuevo valor como operador modal indicador de que el suceso final se ha producido tras una serie de etapas o avatares (12), especialmente en contextos donde el hablante muestra una actitud de expectación ante el hecho referido; este sentido se desarrolla en este siglo y se mantendrá en los posteriores:

(12) Yo he visto, señor, a vuestro infeliz hijo arrastrado por los caballos que su mano ha alimentado. Quiere llamarlos y su voz los espanta. Corren. En breve es una llaga todo

16 Así se registra en Feijoo, donde, probablemente, se utiliza como sinónimo del marcador discursivo finalmente para evitar su repetición: «Mas, finalmente, el mal de los pies viene a ser mal de todo el cuerpo; pues dolientes y lánguidos aquellos, este no puede menos de estar postrado, sin movimiento y fuerzas; y a la postre se introduce el mal en las mismas entrañas, sin perdonar las partes que llaman príncipes, a que se sigue la ruina del todo» (Benito Jerónimo Feijoo, Theatro Crítico Universal, VIII, 1739, $C D H)$.

17 Con una diferencia significativa: al cabo introduce un argumento o conclusión considerados más relevantes en contra de otras expectativas: «Para decir esto habrá un prolijo hablador que gastará horas enteras sin cerrar la boca y al cabo no dirá lo que quiso» (Ignacio de Luzán, Arte de hablar, 1729, CORDE); al fin presenta una justificación en apoyo de una afirmación coorientada con algo dicho o supuesto y antiorientada con otros posibles argumentos expresados o implícitos: «No me detengo en aquel ayre insultante, que reyna en toda apología, porque al fin es un artificio harto vulgarizado en nuestra España» (Benito Jerónimo Feijoo, Cartas eruditas y curiosas, II, 1745, CDH). 
su cuerpo. De nuestros dolorosos gritos resuena la llanura. Su ardor impetuoso al fin se calma (José Cadalso, Suplemento a Los eruditos a la violeta, 1772, CORDE).

Para indicar cierre discursivo, se usan en el Setecientos formaciones que habían adquirido este valor ya en el Medievo: finalmente a mediados del XIII y en fin a finales de ese mismo siglo; su valor de cierre discursivo propicia que el último segmento de una secuencia manifieste una idea final o una conclusión englobadora de todo lo expresado previamente por lo que adquieren un valor de reformulación, desarrollado desde finales del siglo XV en el marcador en fin hasta la época actual y restringido a los siglos XVI y XVII en el caso de finalmente. A partir del XVIII, se delimitan las funciones de ambos marcadores: finalmente señala el segmento que cierra una serie discursiva (13) y, en algunos contextos, presenta el resultado final y esperado tras un largo proceso (14); por su parte, en fin mantiene una función como marcador de cierre discursivo, introduciendo el segmento final que pone término a una sucesión anterior (15), pero muestra un uso predominante como reformulativo, con dos valores fundamentales: a) valor de recapitulación, si se vuelve sobre lo dicho para extraer lo esencial, realizar una síntesis o sacar conclusiones (16); b) valor de cancelación de la validez de lo dicho previamente, si se torna sobre la primera formulación a fin de indicar que la información mencionada carece de relevancia o que no se tiene la intención de continuar con ese tema (17). Esta distribución de los valores de cierre para finalmente y de reformulación para en fin se mantendrá en los siglos posteriores.

(13) Hijo mío, tengo poderosos motivos para complacer a V.R. en la satisfacción de esta demanda: la importancia de el fin, la hermandad de la professión, finalmente, lo mucho que he debido, y aún estoi debiendo, a su padre (Benito Jerónimo Feijoo, Cartas eruditas y curiosas, I, 1742, CDH).

(14) Los italianos padecieron también la misma desventura de ver corrompida su elocuencia y poesía y depravado no menos que nosotros su estilo con las poesías del caballero Marino y de sus secuaces; pero finalmente sacudieron animosos el yugo de la ignorancia y restituyeron a su poesía su primer lustre y belleza (Ignacio de Luzán, La Poética, 1737-1789, CDH).

(15) Estos son los que por tanto tiempo han tenido y tienen tiranizado el teatro español; éstos los que empuercan diariamente los papeles públicos, y éstos, en fin, los que haciéndose intérpretes de la nación que los tolera, se han atrevido al son de zambombas, chiflatos y cencerros, a llorar las desgracias de la patria en la pérdida de sus amados príncipes (Leandro Fernández de Moratín, La derrota de los pedantes, 1789, CDH). 
(16) Es para todos porque de todos se hace amar. Príncipes, y vassallos, grandes y pequeños, señores y populares, togados, religiosos, militares; en fin, todos y de todas classes, desde el instante que empiezan a tratar a V. S. empiezan a amarle (Benito Jerónimo Feijoo, Teatro Crítico Universal, V, 1733, CDH).

(17) No es posible decirte cuanto me hicieron rechinar estas picardías; pero en fin (Leandro Fernández de Moratín, Cartas de 1792 [Epistolario], $C D H$ ).

La locución por fin presenta una función de marcador discursivo desde el siglo XVI en contextos en los que señala el suceso que pone término a una serie de acontecimientos y de ahí el cierre de una ordenación de los miembros discursivos; a diferencia de las otras dos formas, en fin y finalmente, el elemento final que introduce suele implicar un matiz de expectación mediante el que se indica que hubo algunas dificultades hasta lograr que el acontecimiento final se realizase. Este valor de expectación se convierte en relevante en los textos del siglo XVIII y se impondrá a partir de esa época (18), mientras que su empleo como ordenador discursivo queda restringido a contextos en los que se establece una enumeración previa y su empleo es poco frecuente ${ }^{18}$ :

(18) Señor: Ya por fin estoy contento de haber hecho este pie de letras humanas en estos seis libros... (Manuel Díez, Carta a Rodríguez Campomanes, 1773, CORDE).

En cuanto a las construcciones que tienen en su base léxica el ordinal último, se mantienen como marcadores que señalan el miembro final de una serie discursiva lo último, por último ${ }^{19}$, y se incorpora en el XVIII en último lugar con este mismo valor de cierre discursivo que se consolida en el siglo siguiente (19):

(19) Pondremos en último lugar a Henrico Cornelio Agrippa, a quien el padre Martín Delrío da el superlativo epíteto de Archimago (Benito Jerónimo Feijoo, Teatro Crítico Universal, II, 1728, $C D H)$.

18 Se muestra en textos de tipo técnico como en el siguiente ejemplo: «Su método de tratar esta materia, debería ser imitado. Hace primero el escrutinio botánico, luego la análisis chímica, despues pasa á sus virtudes en ciertas enfermedades, y por fin indica sus usos económicos» (Anónimo, Extractos de las Juntas Generales celebradas por la Real Sociedad Bascongada de los Amigos del País, Otros, 1793, CORDE).

19 Lo último se incorpora en el XV, en las series correlativas, lo primero, lo segundo; por último se muestra en correlación con primero, segundo... desde comienzos del XVI. 
En relación con la formación adverbial últimamente, mantiene un empleo como ordenador discursivo para introducir el último elemento de una serie ${ }^{20}$-así se atestigua en el ejemplo 1-, pero con una frecuencia escasa en relación con el valor 'desde un tiempo a esta parte' que comienza a imponerse en este siglo en contextos en los que se alude a procesos o actividades que se han producido reiteradamente desde un tiempo anterior hasta el momento de la enunciación o en los que se hace referencia a estados durativos que se continúan hasta el momento en el que se sitúa el discurso (20); estos valores temporales serán los que se impongan a partir de esta época:

(20) Lo que ciertamente y con grandísima gloria hicieron antaño muchos españoles, altamente instruidos, dotados de talento y sabiduría, lo repitieron últimamente muchos, habiendo publicado sus brillantes escritos y excelentes estudios, y demostrado cuidado y esfuerzo ilimitados (Ignacio de Luzán, Defensa de España y participación en la campaña contra Gregorio Mayans, 1742, $(D H)$.

\section{EL PROCESO DE REFORMULACIÓN EXPLICATIVA Y SUS MARCADORES EN LOS TEXTOS DEL SIGLO XVIII}

Otro procedimiento fundamental en la organización discursiva es la operación de reformulación que implica una vuelta a los segmentos previos para presentarlos desde una nueva perspectiva, equivalente o distinta, que permite la adecuada interpretación del mensaje por parte de los destinatarios. La especificidad de la reformulación, en relación con otras funciones discursivas, "es el proceso retroactivo que permite explicar, rectificar, recapitular, reconsiderar o distanciarse de una formulación anterior" (Garcés Gómez 2008: 69), de donde se derivan los distintos tipos de reformulación establecidos: de explicación, de rectificación, de recapitulación, de reconsideración y de distanciamiento ${ }^{21}$.

20 Este valor de cierre discursivo se registra desde el siglo XV, se mantiene en la época clásica y a partir del siglo XVIII comienza a disminuir en relación con el aumento de su empleo como operador temporal (Vidal Díez \& Burguera Serra 2012).

21 El concepto de reformulación ha sido tratado desde diversas perspectivas teóricas y metodológicas. Gülich \& Kotschi $(1987,1996)$ distinguen entre reformulación parafrástica, considerada como una relación de equivalencia semántico-discursiva o una predicación de identidad, y reformulación no parafrástica, concebida como un cambio de perspectiva de lo expresado en el segmento de referencia al mismo tiempo que se establece un distanciamiento de distinto grado. Roulet (1987), por su parte, afirma que solo es posible hablar de reformulación en el caso de la denominada "reformulación no parafrástica" cuando se establece un cambio de perspectiva enunciativa, dado que la reformulación parafrástica se limita a una relación de paráfrasis. En esta misma línea, Pons Bordería (2013: 157) señala que la paráfrasis debe ser excluida del proceso de reformulación, dado que implica igualdad 
En este ámbito, analizaremos las funciones de reformulación explicativa que se configuran en los textos prosísticos del siglo XVIII y que responden fundamentalmente a dos tipos: a) la relación establecida en el plano de la equivalencia semántico-discursiva con procedimientos que explican, aclaran, matizan o precisan el contenido de lo expresado previamente; b) la relación surgida mediante procesos inferenciales que conducen a interpretar el enunciado de referencia en el sentido establecido en el segmento reformulado.

A lo largo de la historia de la lengua, la operación de reformulación explicativa se manifiesta a través de diversos procedimientos ${ }^{22}$; en esta ocasión, nos centraremos especialmente en el análisis de los marcadores discursivos prototípicos: esto es, a saber, es decir, o sea; en algunos casos, mantienen aún distintos tipos de variación, esto es a saber, conviene a saber, esto es decir, que es decir que; no obstante, a finales de este siglo estas variantes ya son poco utilizadas y quedan fijadas y establecidas las formas canónicas.

La creación de este paradigma de marcadores explicativos responde a dos procesos distintos: las construcciones esto es y a saber, con las variantes esto es a saber, conviene a saber se registran ya en el siglo XIII probablemente como calcos semánticos o traducciones de las formas latinas id est y videlicet respectivamente (Pons Bordería 2006) y están asociadas en estas primeras etapas a tradiciones discursivas vinculadas a textos de tipo jurídico, glosarios, traducciones o textos técnicos; las formaciones es decir y o sea surgen como resultado de un cambio semántico metonímico de carácter inferencial y su evolución está asociada a procesos de gramaticalización por expansión. El origen del marcador es decir está ligado a las construcciones en las que actúa como forma libre con una función oracional en contextos en los que se explica el significado

semántica e igualdad cognitiva, textual o comunicativa, mientras que la reformulación supone un distanciamiento establecido entre el segmento de referencia y el segmento reformulado; en este sentido, el proceso de corrección, que supone la sustitución de un miembro discursivo por otro, también quedaría excluido de las operaciones de reformulación.

Por nuestra parte, consideramos más adecuado caracterizar el concepto de reformulación como un proceso de reinterpretación discursiva consistente en volver sobre un segmento anterior para presentarlo desde una nueva perspectiva y establecer diferentes subtipos de reformulación según el marcador empleado y las relaciones establecidas entre los miembros del discurso en un contexto determinado (Portolés 2004, 2016, Garcés Gómez 2008, Murillo 2016).

22 En los sucesivos periodos de la historia de la lengua se registran expresiones como «que quiere dezir, quiere dezir tanto como, quiere tanto dezir como, es tanto como dezir, o lo que es lo mismo, o lo que es igual, como si dijera (dijéramos), esto sería como si" y otro tipo de construcciones con diversos grados de gramaticalización como "en otras palabras, en otros términos, dicho con/en otras palabras, dicho de otra manera, dicho de otra forma, dicho de otro modo, de otro modo»» (Penas Ibáñez \& Abad Serna 2011: 46). 
de una palabra o de un concepto anterior; el paso a marcador discursivo se produce cuando se convierte en una unidad independiente, con una función de equivalencia discursiva en la que se indica que lo mencionado en el segmento precedente ha de ser interpretado en el sentido que se manifiesta en el segmento reformulado; este valor se muestra desde el siglo XVI, asociado a textos técnicos, científicos y doctrinales y a glosas y traducciones. El origen del marcador $o$ sea, como ha señalado Pons Bordería (2016: 320-321), parte del debilitamiento del significado excluyente de $o$ en la construcción o sea a favor de una lectura incluyente, que evolucionará con el paso del tiempo de la expresión de oposición a la de equivalencia; esta evolución está favorecida por el empleo en géneros discursivos como glosas o traducciones orientados a establecer la semejanza de significados.

Como hemos señalado, en el siglo XVIII, estos marcadores ya están constituidos en la lengua española y se produce en este periodo una simplificación de las variantes formales, atestiguadas en etapas anteriores y mantenidas aún en algunos autores de este siglo, y la incorporación de valores innovadores que se van a extender y ampliar en el siglo siguiente. Hay que señalar, en este aspecto, que en su proceso evolutivo estos marcadores, especialmente es decir y o sea, a partir de su valor originario de equivalencia semántico-discursiva, incorporan nuevos significados que los convierten en unidades polisémicas y polifuncionales. Tanto en el caso de es decir como de o sea desarrollan valores conclusivos, que se muestran de manera incipiente en esta época, y que se desarrollarán en el siglo XIX; por otra parte, es decir adquiere un nuevo valor de rectificación ${ }^{23}$ en el XIX, uso vinculado a los textos literarios, en especial, novelísticos, y o sea desarrolla un valor modal ${ }^{24}$ a partir del siglo XX, ligado al registro coloquial. Analizaremos las formas y funciones de cada uno de estos elementos en el Setecientos.

3.1 El marcador esto es presenta una gran vitalidad, dado que es el más empleado en todos los géneros y tipos de texto en el siglo XVIII para establecer una relación de equivalencia entre el miembro de referencia y el reformulado. Se utiliza en

23 Así aparece especialmente en los textos literarios y, en especial, novelísticos: «Ah! ¡pícara memoria! don Fermín, una palabra, con permiso del señor Arcediano..., es decir, no es una palabra, tenemos que hablar largo... son intereses espirituales» (Clarín (Leopoldo Alas), La Regenta, 1884-1885, CDH)

24 Este valor modal del marcador $o$ sea no forma parte de su funcionamiento como reformulador: «El tabaco es la ruleta rusa, te mata o no, pero, mientras tanto, "fumando espero al hombre que yo quiero", como cantaría Saritísima, porque dicen que "fumar es un placer genial, sensual" (me parece que aquí se pasan un poco, o sea)» (El Mundo, 30/10/1996, Francisco Umbral "Solo fumadores", CREA). 
construcciones en las que se explica el significado de un vocablo o de un sintagma mediante una expresión equivalente (21) o se aclara el sentido en que ha de entenderse un concepto (22):

(21) No juzgo absolutamente imposible el que con algunas tinturas penetrantes, que no son incógnitas a los chímicos, se pinte en una piedra algún objeto, de modo que no parezca la representación artificiosa, sino natural; esto es, que sus colores parezcan nativos de las betas de la piedra, y no inducidos por arte (Benito Jerónimo Feijoo, Teatro Crítico Universal, VII, 1736, CDH).

(22) No sería tampoco, a mi juicio, cuidado indigno del celo y la previsión del gobierno el buscar maestros extranjeros o enviar jóvenes a viajar e instruirse fuera del reino y establecer después una escuela práctica para la educación de nuestros comediantes, porque si el teatro ha de ser lo que debe, esto es, una escuela de educación para la gente rica y acomodada, ¿qué objeto merecería más su desvelo que el de perfeccionar los instrumentos y arcaduces que deben comunicarla y difundirla? (Gaspar Melchor de Jovellanos, Memoria para el arreglo de la policía de los espectáculos y diversiones públicas, 1790-1796, CDH).

Asimismo, este marcador se emplea para explicar el significado de un término técnico mediante su definición (23) o a fin de concretar lo manifestado en un miembro anterior a través de una denominación más específica (24):

(23) Pero ves aquí que, cuando la gente del chilindrón estaba en lo mejor de su trisca y el bendito fray Gerundio más engolfado en sus glorias, entraron en su celda el prelado, el maestro fray Prudencio y los demás padres graves a darle la que llaman la acenoria; esto es, la enhorabuena de la función, como loablemente se estila en todas las religiones (José Francisco Isla, Historia del famoso predicador Fray Gerundio de Campazas alias Zotes, 1758, CDH).

(24) Como salió tan buen pendolista, desde luego hizo ánimo a seguir la carrera de las escuelas; esto es, a ser maestro de niños (José Francisco Isla, Historia del famoso predicador Fray Gerundio de Campazas alias Zotes, España, 1758, CDH).

El empleo del marcador permite interpretar lo expresado en el enunciado de referencia en el sentido manifestado por el escritor, que considera el más apropiado en ese contexto, especialmente en los textos novelísticos y en las secuencias narrativas (25):

(25) Para esto, claro está que es indispensablemente necesario que el predicador tenga en cierto modo un conocimiento casi intuitivo de las verdades y de los misterios de la 
religión; esto es, que los comprenda todo cuanto es posible comprenderlos en esta vida (José Francisco Isla, Historia del famoso predicador Fray Gerundio de Campazas alias Zotes, 1758, $\mathrm{CDH})$.

3.2 El marcador a saber convive con las variantes conviene a saber, es a saber en los autores que redactan sus obras en las primeras etapas del siglo XVIII; posteriormente, algunos escritores como Luzán, Forner, Mayans y Siscar, Feijoo o Isla usan la variante elidida $a$ saber junto con las otras variantes, mientras que otros más innovadores como Cadalso o Jovellanos optan por el empleo únicamente de la formación a saber.

El empleo de las formaciones conviene a saber y es a saber aparece en contextos semejantes: cuando se especifican las partes a las que se refiere lo expresado en un constituyente anterior (26) o cuando se explica el significado de un concepto aludido en el segmento de referencia (27):

(26) Lo que es de mayor momento, si no el todo, en esta parte, es, que en todas aquellas cosas, que essencialmente componen la felicidad temporal, conviene a saber, vida, salud, honra y hazienda, es muy mejorado el virtuoso, respecto de el que no lo es (Benito Jerónimo Feijoo, Teatro Crítico Universal, I, 1726, $C D H)$.

(27) Por último, para decir en una palabra mi sentir, le circunscribo al apotegma a que redujo el suyo el insigne doctor Martínez sobre doña Oliva, es a saber: "Que este libro sólo falta, como otros muchos sobran" (José Francisco Isla, Historia del famoso predicador Fray Gerundio de Campazas alias Zotes, 1758, CDH).

En este tipo de contextos, el marcador a saber se utiliza para especificar tanto el referente como el contenido de lo expresado en un segmento precedente (28):

(28) En todo esto no hallo más que un solo, y leve inconveniente, a saber, que con el imperfecto conocimiento de tantos idiomas olvidéis el de vuestro mismo país (José Cadalso, Los eruditos a la violeta, 1772, CORDE).

Se muestra también en construcciones en las que se define el significado de un nuevo concepto creado por el escritor; como en el ejemplo siguiente (29), donde se dota de un sentido específico al sintagma erudito a la violeta que da título a la obra del autor:

(29) Pero si se entiende por erudito a la violeta lo que yo entiendo, y quise que todos entendiesen desde que puse la pluma al papel; a saber, uno que sabiendo poco, aparente mucha ciencia, digo que no se me parece la pintura ni en una pincelada (José Cadalso, Suplemento a Los eruditos a la violeta, 1772, CORDE). 
Y se utiliza especialmente en los textos técnicos y científicos cuando se establece la relación de los componentes de un constituyente definido o se realiza la enumeración de sus partes (30); este significado será el prototípico de este marcador:

(30) El Abate de Condillac señaló cinco operaciones a la que él quiso llamar también alma de los brutos: a saber, la percepción, la conciencia, la atención, la reminiscencia y la imaginación (Juan Pablo Forner, Discursos filosóficos sobre el hombre, 1787, CDH).

3.3 El marcador es decir se emplea en el siglo XVIII de forma generalizada como reformulador explicativo y, en algunos casos concretos, se documenta la expresión que es decir. La construcción esto es decir ${ }^{25}$ se registra especialmente en la obra de Feijoo, autor muy cercano a los modos de expresión de la lengua francesa, por lo que su empleo en los textos de este escritor se puede explicar por su equiparación con el marcador francés $c$ 'est-à-dire, que presenta este valor explicativo desde el siglo XV (TFli s.v. c'est-à-dire). A finales del XVIII se impone la variante es decir como construcción consolidada.

El empleo de este marcador se muestra en reformulaciones de tipo explicativo cuando un miembro discursivo o un enunciado es formulado de nuevo para aclarar lo que se ha pretendido comunicar y que, de este modo, el interlocutor pueda comprenderlo de una manera adecuada (31):

(31) Esta reflexión es más poderosa cuando se considera la naturaleza de uno y otro monopolio, o llámese comercio. El negociante, por el espíritu de su profesión, funda sus ganancias más bien en el número que en el resultado de sus especulaciones, es decir, quiere más una ganancia mayor, compuesta de muchas pequeñas, que una grande, producida por una sola empresa (Gaspar Melchor de Jovellanos, Informe de la Sociedad Económica de Madrid, 1794, CDH).

La explicación también se manifiesta a través de la relación de los componentes que se incluyen en un concepto expresado en el segmento de referencia (32):

25 Casado Velarde (1996: 323) considera que la forma esto es decir podría ser un galicismo gramatical. No obstante, esta construcción se documenta en la lengua española desde el siglo XV (Herrero Ingelmo 2007) en contextos en los que establece una equivalencia significativa entre dos segmentos, por lo que su proceso evolutivo pudo estar originado por un cambio semántico de carácter metonímico ligado a este tipo de estructuras contextos; de este modo se trataría de una forma autóctona que pudo incrementar su empleo en el siglo XVIII, especialmente en autores cercanos a la cultura francesa. 
(32) Ahora sucede que por lo regular ó un director inesperto, ó un escribano tan ignorante como hablador ó caviloso, son dueños de vestir a su arbitrio, como ellos dicen, los contratos y escrituras que otorgan; es decir, de acumular palabras y razones inútiles, viciosas, oscuras, contradictorias, en que después hallan las partes y sus abogados un arsenal copioso de armas y fundamentos acomodados a las pretensiones más opuestas (Juan Meléndez Valdés, Discursos forenses, 1791-1809, CDH).

O mediante la interpretación de un enunciado expresado por un locutor distinto; en este caso se alude al autor de la cita mediante el estilo indirecto (33) y se explica el sentido que hay que dar a ese fragmento de tipo doctrinal:

(33) A mas se estiende el divino Sales, quando dice (Práctica del amor de Dios, Lib. 2, cap. 8) que el amor es el medio universal de nuestra salud, el qual se mezcla en todo, y sin él nada hay saludable. Esto es decir, que el amor es el remedio universal para las enfermedades del alma (Benito Jerónimo Feijoo, Cartas eruditas y curiosas, V, 1760, CDH).

Asimismo, el miembro en el que se sitúa se presenta como una reformulación explicativa en la que se aclara el significado de una expresión o de una paremia (34):

(34) Quien miente, no viene de buena gente. Esto es decir, que es calidad privativamente propia de los nobles ser mentirosos (Benito Jerónimo Feijoo, Cartas eruditas y curiosas, III, 1750, $C D H)$.

Tanto el marcador es decir (35) como la expresión que es decir (36) pueden desarrollar procesos inferenciales cuando se utilizan para derivar la conclusión que se extrae de lo manifestado en los segmentos anteriores; este será el significado, junto con el de reformulación explicativa, que mantendrá el marcador discursivo es decir en los siglos siguientes:

(35) Un teatro tal, después de entretener honesta y agradablemente a los espectadores, iría también formando su corazón y cultivando su espíritu; es decir, que iría mejorando la educación de la nobleza y rica juventud, que de ordinario le frecuenta (Gaspar Melchor de Jovellanos, Memoria para el arreglo de la policía de los espectáculos y diversiones públicas, 1790-1796, CDH).

(36) He acabado ya el encargo de la Garitera: es una zarzuelilla en dos actos intitulada el Barón; yo no he puesto gran cuidado en ella, que es decir que será detestable (Leandro Fernández de Moratín, Cartas de 1787 [Epistolario], $C D H$ ). 
3.4 El marcador o sea es el que presenta un mayor número de funciones en este siglo (Pons Bordería 2016). Se utiliza para establecer la equivalencia entre dos miembros discursivos cuando introduce una explicación del significado de un segmento anterior (37):

(37) De estos trata Nuño algunos de los que residen en Madrid, y los quiere como paisanos suyos, pues tales le parecen todos los hombres de bien del mundo, siendo para con ellos un verdadero cosmopolita, o sea ciudadano universal (José Cadalso, Cartas marruecas, 1774-1778, CDH).

O cuando se trata de una aclaración del sentido en el que ha de entenderse lo formulado en el segmento de referencia (38):

(38) Muratori, que con tanto acierto ha escrito de la belleza poética, es de opinión que, como la utilidad es producida por lo bueno, o sea, por la bondad unida con la verdad, así el deleite poético procede de la belleza fundada en la verdad (Ignacio Luzán, Arte de hablar, 1729, CORDE).

Comienza a extenderse el empleo de marcador para establecer una conclusión extraída a partir de lo expresado en los segmentos anteriores mediante un proceso inferencial (39) ${ }^{26}$ :

(39) No, sino que dentro de pocos días perdió trágicamente Ptolomeo el reino y la vida, y murieron desdichadamente los tres autores y executores de la muerte de Pompeyo, Theodoto, Aquilas y Photino; o sea, que las máximas impías por su naturaleza son aptas a producir infortunios (Benito Jerónimo Feijoo, Teatro Crítico Universal, V, 1733, ejemplo incluido en Pons Bordería 2016).

Surge un nuevo valor en este siglo cuando el segmento en el que se sitúa el marcador se plantea como una nueva formulación alternativa considerada más adecuada al contexto que la enunciación anterior; este proceso retroactivo implica introducir un nuevo punto de vista, de ahí su empleo preferente en contextos polifónicos donde el locutor presenta las voces de dos enunciadores distintos (Ducrot 1984), uno que se manifiesta en el segmento de referencia y otro, identificado con el locutor, que se

26 En el siglo XVII, se documenta un solo ejemplo de $o$ sea con valor conclusivo en un texto de 1613 de Quevedo, según señala Pons Bordería (2016: 321), y es en el XVIII cuando se vuelve a documentar este valor que se mantendrá en el siglo XIX y ampliará su frecuencia en el español contemporáneo (Pons Bordería 2016). 
expresa en el segmento reformulado y que supone la reinterpretación del miembro precedente; este empleo está asociado al género novelístico (40):

(40) Sin querer he dicho ya a vuestra merced en estas últimas expresiones cuanto siento y todo mi dictamen en orden al entusiasmo o novela de su héroe - o sea, figurón-, de fray Gerundio (José Francisco de Isla, Historia del famoso predicador Fray Gerundio de Campazas alias Zotes, 1758, ejemplo incluido en Pons Bordería 2016).

\section{CONCLUSIONES}

La primera etapa del español moderno muestra la extensión y arraigo de nuevas tradiciones discursivas que suponen un nuevo modo de organizar y planificar el discurso. En este sentido, los marcadores de ordenación y de reformulación explicativa que hemos analizado representan un papel fundamental en este modelo de organización del discurso, pues sus funciones y valores se mantendrán y se ampliarán en los siglos siguientes ${ }^{27}$.

En el grupo de los marcadores de ordenación discursiva, se consolida el valor de prioridad del operador primeramente; se mantienen los pares correlativos de una parte... de otra, por una parte... por otra, por un lado... por otro, y se incorpora al paradigma la correlación de un lado... de otro con la función de delimitar las partes en las que se estructura una serie; estos marcadores se muestran como sinónimos, con diferencias en cuanto a la mayor frecuencia de uso de los dos primeros correlatos. Del mismo modo, quedan incorporadas las formas que no presentan un primer correlato - de otra parte, por otra parte- surgidas en una etapa anterior y aparecen en este siglo las formaciones de otro lado, por otro lado; como en los pares correlativos, las diferencias vienen dadas por la mayor frecuencia de uso de las dos primeras formaciones, ya que los cuatro elementos se utilizan como sinónimos con los valores específicos

27 Girón Alconchel (2003) realizó un estudio de la evolución del discurso ensayístico a partir del análisis de tres capítulos de sendos ensayos de Gracián (Discurso XLVII de Agudeza y arte de ingenio, 1648), Gutiérrez de los Ríos (Discurso XXX de El hombre práctico, 1686) y de Feijoo ("Prólogo al lector" del Teatro Crítico Universal, 1726) y concluyó que «a diferencia de otros marcadores del discurso, los conectores van aumentando cuantitativa y cualitativamente desde 1648 a 1726. Coincide este aumento con el de la hipotaxis en el interior de las oraciones y cláusulas y evidencia que la cohesión de los textos ensayísticos en el tránsito del siglo XVII al XVIII descansa en gran parte en las relaciones de adición, de contraste y de causalidad» (Girón Alconchel 2003: 350). Compartimos esta afirmación, pero es manifiesto que el empleo de ordenadores y de reformuladores explicativos en la estructuración del discurso se consolida durante el Setecientos en las funciones $\mathrm{y}$ valores que se van a mantener y ampliar en el XIX y XX. 
de transición entre enunciaciones o de comentario digresivo. En los marcadores de cierre, quedan distribuidas en esta etapa las funciones de finalmente, como marcador de cierre discursivo con un valor resultativo en determinados contextos, y de en fin como marcador de reformulación, aunque este puede mantener, en algunos casos, su valor originario de ordenador discursivo cuando introduce un segmento que señala el cierre de una sucesión. Surge la formación en último lugar para indicar el cierre de una serie enumerativa, que sustituye a últimamente en su valor de cierre discursivo, ya que el adverbio desarrolla en esta etapa su valor temporal. Por fin mantiene empleos como cierre discursivo pero con escasa frecuencia en relación con la consolidación del valor modal, que será el único que presente el operador al fin; en ambos casos, su sentido es el de indicar que un hecho se ha producido tras una serie de avatares anteriores y el hablante destaca el momento o situación final que culmina el proceso.

En cuanto a la distribución de estos ordenadores discursivos según los géneros, se utilizan fundamentalmente en ensayos y tratados técnicos y científicos, especialmente en secuencias expositivas y, con menor proporción, en secuencias narrativas o descriptivas, que son, por el contrario, aquellas en las que estos marcadores se muestran de modo más habitual en el género epistolar y en la novela. Los operadores discursivos al fin y por fin, que adquieren el valor modal de indicar la expectación ante un hecho, se muestran fundamentalmente en el género novelístico y en el epistolar, así como en el ensayístico en secuencias donde el hablante/escritor muestra una opinión subjetiva ante una determinada situación.

En el grupo de los marcadores de reformulación explicativa, las formaciones esto es y a saber quedan como sintagmas fijos, pues las variantes esto es a saber, conviene a saber tienen un empleo muy limitado. La construcción es decir se consolida como marcador, mientras que la variantes esto es decir, mantenida en autores como Feijoo, por influencia del francés c'est-à-dire, ya no se emplea a finales de siglo, y también queda muy limitado el uso de la expresión que es decir que; la formación $o$ sea ya está plenamente gramaticalizada. En relación con los valores que presentan estos elementos, todos comparten una función común de reformulación por la que se establece una equivalencia discursiva entre el miembro reformulado y el segmento de referencia, pero con diferencias que permiten establecer características distintivas para cada uno de ellos. Por otra parte, en su desarrollo evolutivo, los marcadores $o$ sea y es decir se han convertido en signos polisémicos y polifuncionales que han desarrollado nuevas funciones discursivas.

Como marcador de reformulación, esto es se utiliza en contextos en los que se explica el significado de un término o el sentido en el que ha de entenderse un concepto o un enunciado; a saber se emplea en la reformulación explicativa con 
preferencia en contextos en los que en el segmento reformulado se da una relación de los componentes de un constituyente definido o una enumeración de sus partes; es decir mantiene una dimensión explicativa y desarrolla a partir de esta época un valor conclusivo inferencial que se extenderá en el siglo XIX; o sea se muestra en tres tipos de contextos: aquellos en los que se establece una equivalencia discursiva entre los segmentos enlazados, en los que se señala una conclusión derivada de lo expresado en los miembros precedentes a través de un proceso inferencial y en los que la reformulación se presenta como una forma alternativa de expresar lo manifestado en un segmento anterior. En cuanto a la distribución por géneros, esto es y a saber aparecen en textos técnicos, científicos, ensayísticos y novelísticos con preferencia en registros formales; es decir y o sea se documentan en textos ensayísticos, técnicos y científicos, así como en el género epistolar y novelístico, con un empleo en estos dos últimos en los registros menos formales.

Partíamos de la hipótesis de que en esta primera etapa del español moderno se desarrollan nuevas tradiciones discursivas que traen consigo nuevos modelos de organización del discurso manifestándose en una forma de expresión más sencilla a la vez que más precisa y más matizada; esto supone que los ordenadores y reformuladores explicativos utilizados en los textos de este periodo muestren, por un lado, una delimitación y simplificación de las variantes formales y una distribución de las funciones de cada uno de los marcadores en sus respectivos paradigmas y, por otro, la pérdida de valores discursivos en algunos elementos y la adquisición de nuevas funciones discursivas en los que se incorporan más tardíamente que se consolidarán en los siglos siguientes y se ampliarán, en el caso de es decir, con un valor de rectificación en el siglo XIX (Casado Velarde 1996) y en el de o sea con un valor modal, fuera ya del ámbito de la reformulación, que surge en el XX (Pons Bordería 2016).

\section{BIBLIOGRAFÍA}

\section{Fuentes consultadas}

BDH. Biblioteca Nacional de España. Biblioteca Digital Hispánica [en línea]. $<$ http:// www.bne.es/es/Catalogos/BibliotecaDigitalHispanica/Inicio/index.htm $>$ [Fecha de consulta: diciembre 2017-abril 2018].

$C D H$. Instituto de Investigación Rafael Lapesa de la Real Academia Española. Corpus del Nuevo diccionario histórico de la lengua española [en línea]. <http://www. rae.es> [Fecha de consulta: diciembre 2017-abril 2018]. 
CE. Mark Davies. Corpus del Español: 100 million words, 1200s-1900s [en línea]. $<$ http://www.corpusdelespanol.org $>$ [Fecha de consulta: diciembre 2017-abril 2018].

CV. Biblioteca Virtual Miguel de Cervantes [en línea]. $<$ http://www.cervantes virtual. com> [Fecha de consulta: diciembre 2017-abril 2018].

CORDE. Real Academia Española. Corpus Diacrónico del Español [en línea]. $<$ http:// www.rae.es> [Fecha de consulta: diciembre 2017-abril 2018].

TLFi: Trésor de la Langue Française Informatisé. $<$ http://atilf.atilf.fr/tlf.htm> [Fecha de consulta: marzo-abril 2018].

\section{Referencias bibliográficas}

BRINTON, L. J. (2001): "Historical discourse analysis", in D. Schiffrin, D. Tannen \& H. E. Hamilton (eds.): The Handbook of Discourse Analysis. Oxford: Blackwell, pp. $138-160$.

Brinton, L. J. (2010): “Discourse markers”, in A. H. Jucker \& I. Taavitsainen (eds.): Historical Pragmatics. Berlin / New York: De Gruyter, pp. 285-314.

CANO, R. (1999): “La construcción del discurso en el siglo XIII: diálogo y narración en Berceo y el Alexandre", Moenia 5, pp. 257-269.

CANO, R. (2001): "La cohesión gramatical del discurso en el castellano del siglo XV", in E. Méndez, J. Mendoza \& Y. Congosto (eds.): Indagaciones sobre la lengua. Estudios de filología y lingüistica españolas en memoria de Emilio Alarcos. Sevilla: Universidad de Sevilla, pp. 181-201.

Cano, R. (2002): "Elementos de ilación textual en castellano medieval (época post-alfonsí)", in M. ${ }^{a}$ T. Echenique \& J. Sánchez (eds.): Actas del V Congreso Internacional de Historia de la Lengua Española. Madrid: Arco Libros, vol. 1, pp. 279-284.

CANO, R. (2003): "Función sintáctica, significación gramatical y valor léxico en la conexión supraoracional”, in J. L. Girón et al. (eds.): Estudios ofrecidos al profesor José Jesús de Bustos Tovar. Madrid: Universidad Complutense, vol. 1, pp. 297-314.

CANO, R. (2007): “Conectores del discurso en el español del siglo XVI”, Lexis XXXI/ 1 y 2 , pp. 5-45.

Casado Velarde, M. (1996): "Notas sobre la historia de los marcadores textuales de explicación es decir y o sea", en M. Casado Velarde et al. (eds.): Scripta 
Philologica in memoriam Manuel Taboada Cid. La Coruña: Universidad de La Coruña, vol. 1, pp. 321-328.

Claridge, C. \& L. Arnovick (2010): "Pragmaticalisation and discursivisation", in A. H. Jucker \& I. Taavitsainen (eds.): Historical Pragmatics. Berlin / New York: De Gruyter, pp. 165-192.

Company Company, C. (2016): "Gramaticalización y cambio sintáctico", in J. Gutiérrez Rexach (ed.): Enciclopedia Lingüistica Hispánica. London / New York: Routledge, vol. 2, pp. 515-526.

Croft, W. (2007): "Construction grammar", in D. Geeraerts \& H. Cuykens (eds.): The Oxford Handbook of Cognitive Linguistics. New York: Oxford University Press, pp. 463-508.

De Beaugrande, R. A. \& W. U. Dressler (1981): Einführung in die Textlinguistik. Tübingen: Max Niemeyer. https://doi.org/10.1515/9783111349305

DiewALD, G. (2002): "A model for relevant types of contexts in grammaticalization", in I. Wischer \& G. Diewald (eds.): New reflections on grammaticalization. Amsterdam: John Benjamins, pp.103-120. https://doi.org/10.1075/ts1.49.09die

Díez Del Corral, E. (2015): "El siglo XIX y su relevancia en el estudio histórico de algunos marcadores discursivos", Études romanes de Brno 36/1, pp. 21-39.

Ducrot, O. (1984): "Esquisse d'une théorie polyphonique de l'enonciation", in O. Ducrot (ed.): Le dire et le dit. Paris: Minuit, pp. 171-233.

ELVIRA, J. (2015): Lingüistica histórica y cambio gramatical. Madrid: Síntesis.

EsPinosa ElorZA, R. M. (2012a): "Novedades del siglo XVIII en aspectos relacionados con los cambios gramaticales", in M. ${ }^{a}$ T. García-Godoy (ed.): El español del siglo XVIII. Cambios diacrónicos en el primer español moderno. Berlin / Oxford / Wien: Peter Lang, pp. 85-109.

Espinosa Elorza, R. M" (2012b): "Cambios sintácticos en el siglo XIX”, en J. L. Ramírez Luengo (ed.): Por sendas ignoradas. Estudios sobre el español del siglo $X I X$. Lugo: Axac, pp. 61-74.

Estellés, M. (2011): Gramaticalización y paradigmas. Un estudio a partir de los denominados marcadores de digresión en español. Frankfurt: Peter Lang. https:// doi.org/10.3726/978-3-653-00952-1

Flores, M. \& Melis, Ch. (2015): "Periodización del español. Evidencia para una tercera etapa evolutiva", Études romanes de Brno 36/2, pp. 11-28. 
Garachana, M. (2008): "En los límites de la gramaticalización. La evolución de encima (de que) como marcador discursivo", Revista de Filología Española 88/1, pp. 7-36. https://doi.org/10.3989/rfe.2008.v88.i1.43

GARCÉs Gómez, M. ${ }^{a}$ P. (2006): "La evolución de los marcadores de ordenación discursiva en español", Romanistisches Jahrbuch 57, pp. 327-351.

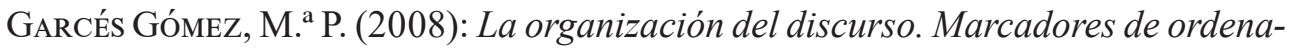
ción y de reformulación. Madrid / Frankfurt: Iberoamericana / Vervuert.

Garcés Gómez, M. ${ }^{a}$ P. (2009): "El proceso evolutivo de los marcadores de reconsideración”, Romanistisches Jahrbuch 60, pp. 215-238.

GARCÉs Gómez, M. ${ }^{a}$ P. (2011): "Paradigma y gramaticalización: el proceso evolutivo de los marcadores de separación", Romanistisches Jahrbuch 62, pp. 289-313. https://doi.org/10.1515/roma.62.10

GARCÉS GóMEZ, M. ${ }^{a}$ P. (2013): "La formación y evolución del paradigma de los operadores discursivos matizadores de la veracidad del enunciado", in M. ${ }^{\mathrm{a}} \mathrm{P}$. Garcés Gómez (ed.): Adverbios con función discursiva. Procesos de formación y evolución. Madrid / Frankfurt: Iberoamericana / Vervuert, pp. 275-316. https:// doi.org/10.31819/9783954872015-009

GARCÉs GóMEZ, M. ${ }^{a}$ P. (2014): “Gramaticalización y tradiciones discursivas. El proceso de creación de los marcadores de confirmación”, Revue Romane 49/2, pp. 264-292. https://doi.org/10.1075/rro.49.2.04gar

Girón ALCONCHEL, J. L. (2003): "Evolución de la cohesión en el discurso ensayístico entre 1648 y 1726", in J. L. Girón Alconchel, et al. (eds.): Estudios ofrecidos al profesor José Jesús de Bustos Tovar. Madrid: Editorial Complutense, vol. 1, pp. 331-360.

Goldberg, A. E. (2006): Constructions at Work: The Nature of Generalization in Language. Oxford: Oxford University Press.

Gülich E. \& Tн. Котsсhi (1987): "Reformulierungshandlungen als Mittel der Textkonstitution. Untersuchungen zu französischen Texten aus mündlicher Kommunikation", in W. Motsch (ed.): Satz, Text, sprachliche Handlung. Berlin: Akademie Verlag, pp. 199-261.

Gülich E. \& TH. KoтsChi (1996): "Textherstellungsverfahren in mündlicher Kommunikation. Ein Beitrag am Beispiel des Französischen”, en W. Motsch (ed.): Ebenen der Textstruktur. Sprachliche und kommunikative Prinzipien. Tübingen: Max Niemeyer, pp. 37-80. https://doi.org/10.1515/9783110918533.37 
Hansen, Maj-Britt M. \& C. Rossari, C. (2005): “The evolution of pragmatic markers. Introduction", Journal of Historical Pragmatics 6/2, pp. 177-187. https://doi. org/10.1075/jhp.6.2.02mos

HeINE, B. (2002): "On the role of context in grammaticalization", in I. Wischer \& G. Diewald (eds.): New reflections on grammaticalization. Amsterdam: John Benjamins, pp. 83-101. https://doi.org/10.1075/ts1.49.08hei

Herrero Ingelmo, J. L. (2007): “Cómo surgen los conectores: los reformuladores id est, esto es, es decir", Revista de Lexicografia 13, pp. 45-54. https://doi. org/10.17979/rlex.2007.13.0.4784

Hopper, P. J. \& Traugott, E. C. (2003²): Grammaticalization. Cambridge: Cambridge University Press.

Iglesias, Silvia (2007): "Marcadores del discurso e historia del español: al fin, en fin, finalmente", in I. Delgado Cobos \& A. Puigvert Ocal (eds.): Ex admiratione et amicitia. Homenaje a Ramón Santiago. Madrid: Orto, vol. 2, pp. 623-645.

JACOBS, A. \& A. Jucker (1995): "The historical perspective in Pragmatics", in A. Jucker (ed.): Historical Pragmatics. Philadelphia: John Benjamins, pp: 3-36.

JАСOB, D. \& J. KABATEK (2001): “Introducción: Lengua, texto y cambio lingüístico en la Edad Media", in D. Jacob \& J. Kabatek (eds.): Lengua medieval y tradiciones discursivas en la Península Ibérica. Descripción gramatical - pragmática histórica - metodología. Madrid / Franfurt: Iberoamericana/Vervuert, pp. VII-XVIII.

KLoss, H. (1967): “Abstand Languages and Ausbau Languages”, Anthropological Linguistics 9, pp. 29-41.

Косн, P. (2001): "Metonymy: Unity in Diversity", Journal of Historical Pragmatics 2, pp. 201-244. https://doi.org/10.1075/jhp.2.2.03koc

Kосн, P. (2004): "Metonymy between pragmatics, reference and diachrony", Metaphorik. de 7. [http://www.metaphoric.de/07/Koch.pdf]

Koch, P. \& W. OESTERREICHER (1990/2007): Gesprochene Sprache in der Romania: Französisch, Italienisch, Spanisch. Tübingen: Max Niemeyer. Versión española de Araceli López Serena. Madrid: Gredos, 2007.

LAPESA, R. (19819): Historia de la lengua española. Madrid: Gredos.

Lehmann, CH. (1995): Thoughts on Grammaticalization. München / Newcastle: Lincom Europa.

Martín Zorraquino, M. a A. \& J. Portolés (1999): "Los marcadores del discurso", in I. Bosque y V. Demonte (eds.): Nueva gramática descriptiva de la lengua española. Madrid: Espasa-Calpe, vol. 3, pp. 4051-4213. 
Melis, Ch., M. Flores \& S. Bogard, S. (2003): "La historia del español. Propuesta de un tercer periodo evolutivo", Nueva Revista de Filología Hispánica 51/1, pp. 1-56. https://doi.org/10.24201/nrfh.v51i1.2202

MuRILLO, S. (2016): "Sobre la reformulación y sus marcadores", Cuadernos AISPI 8, pp. 237-258.

Octavio de Toledo y Huerta, Á. S. (2016): “Aprovechamiento del CORDE para el estudio sintáctico del primer español moderno (ca. 1675-1825)", in J. Kabatek (ed.): Lingüistica de corpus y lingüistica histórica iberorrománica. Berlin / Boston: De Gruyter, pp. 57-89.

Oesterreicher, W. (1997): "Zur Fundierung von Diskurstraditionen”, in B. Frank et al. (eds.): Gattungen mittelalterlicher Schriftlichkeit. Tübingen: Narr, pp. 19-41.

OESTERREICHER, W. (2007): “Gramática histórica, tradiciones discursivas y variedades lingüísticas. Esbozo programático", Revista de Historia de la lengua española 1, pp. 109-128.

PenAs IbÁÑEZ, M. a A. \& ABAD SeRna, S. (2011): “Aproximación histórica a la reformulación lingüística de la paráfrasis como un caso de sinonimia sintagmática", Energeia 3, pp. 30-74.

Pons Bordería, S. (2006): “Gramaticalización por tradiciones discursivas: el caso de esto es", in J. Kabatek (ed.): Sintaxis histórica del español: Nuevas perspectivas desde las Tradiciones Discursivas. Madrid / Frankfurt: Iberoamericana / Vervuert, pp. 249-274.

Pons BorderíA, S. (2013): “Un solo tipo de reformulación”, Cuadernos AISPI 2, pp. 151-170.

Pons Bordería, S. (2016): «Evolución diacrónica de "o sea"», Boletín de la Real Academia Española 96, pp. 291-350.

Pons Bordería, S. \& Ó. Loureda LAMAS (eds.) (2018): Beyond Grammaticalization and Discourse Markers. Leiden / Boston: Brill. https://doi.org/10.1163/9789004375420

Pons Rodríguez, L. (2010): "Los marcadores del discurso en la historia del español", in Ó. Loureda Lamas \& E. Acín Villa (coords.): Los estudios sobre marcadores del discurso en español, hoy. Madrid: Arco Libros, pp. 523-615.

Pons Rodríguez, L. (2015): "Prejuicios y apriorismos en la investigación histórica sobre marcadores discursivos (con algunas notas sobre 'así las cosas')", in M. Borreguero Zuloaga \& S. Gómez-Jordana Ferary (eds.): Marqueurs du discours dans les langues romanes: une aproche contrastive. Limoges: Lambert Lucas, pp. 285-303. 
PortolÉs, J. (2001²): Marcadores del discurso. Barcelona: Ariel, $2^{\mathrm{a}}$ ed. ampliada y actualizada.

Portolés, J. (2004): Pragmática para hispanistas. Madrid: Síntesis.

PortolÉs, J. (2016): “Los marcadores del discurso", in J. Gutiérrez Rexach (ed.): Enciclopedia Lingüistica Hispánica. London / New York: Routledge, vol. 1, pp. 689-699.

Roulet, E. (1987): “Complétude interactive et connecteurs reformulatifs", en: Cahiers de Linguistique Française 8, pp. 111-140.

SÁez Rivera, D. \& M. Guzmán Riverón (eds.) (2016): Márgenes y centros en el español del siglo XVIII. Valencia: Tirant lo Blanch.

SÁnchez López, C. (1999): "Los cuantificadores: Clases de cuantificadores y estructuras cuantificativas", in I. Bosque \& V. Demonte (eds.): Nueva gramática descriptiva de la lengua española. Madrid: Espasa-Calpe, vol. 1, pp. 1025-1188.

SPERBER, D. \& D. Wilson (19952): Relevance. Oxford: Blackwell, $2^{\mathrm{a}}$ ed. revisada y aumentada.

SweETSER, E. (1990): From Etymology to Pragmatics: Metaphorical and Cultural Aspects of Semantic Structure. Cambridge: Cambridge University Press. https:// doi.org/10.1017/CBO9780511620904

Traugott, E. C. (2010a): “Grammaticalization”, in S. Luraghi \& V. Bubenik (eds.): Continuum Companion to Historical Linguistics. London / New York: Continuum International Publishing Group, pp. 269-283.

Traugott, E. C. (2010b): “(Inter)subjectivity and (inter)subjectification: A reassessment”, in K. Davidse et al. (eds.): Subjectification, Intersubjectification and Grammaticalization. Berlin / New York: De Gruyter, pp. 29-71. https://doi. org/10.1515/9783110226102.1.29

Traugott, E. C. \& R. B. Dasher (2002): Regularity in semantic change. Cambridge: Cambridge University Press.

Traugott, E. C. \& E. KöNIG (1991): "The semantics-pragmatics of grammaticalization revisited", in E. C. Traugott \& B. Heine (eds.): Approaches to Grammaticalization. Amsterdam / Philadelphia: John Benjamins, vol. 1, pp. 189-218. https:// doi.org/10.1075/tsl.19.1.10clo

Traugott, E. C. \& G. B. Trousdale (2013): Constructionalization and constructional changes. Oxford: Oxford University Press. https://doi.org/10.1093/acprof:oso/9780199679898.001.0001 
VAn Kuppevelt, J. (1995a): "Discourse structure, topicality and questioning", Journal of Linguistics 3, pp. 109-147. https://doi.org/10.1017/S002222670000058X

VAn Kuppevelt, J. (1995b): "Main structure and side structure in discourse", Linguistics 33, pp. 809-833.

Vidal Díez, M. \& J. Burguera Serra (2012): "Últimamente: cambio funcional y semántico", Verba Hispanica XX/1, pp. 393-410. https://doi.org/10.4312/ vh.20.1.393-410

Zamorano Aguilar, A. (coord. y ed.) (2012): Reflexión lingüistica y lengua en la España del siglo XIX: marcos, panoramas y nuevas aportaciones. München: Lincom. 
